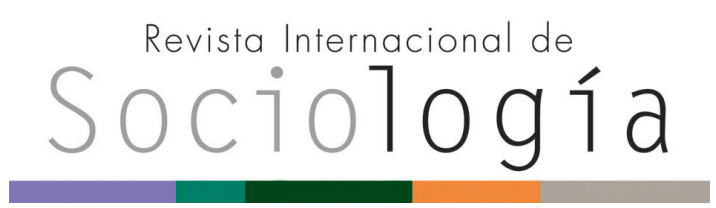

Revista Internacional de Sociología RIS vol. 73 (2), e008, mayo-agosto, 2015, ISSN-L:0034-9712 DOl: http://dx.doi.org/10.3989/ris.2013.07.21

\section{RECOGNITION IN MULTICULTURAL SOCIETIES Intergroup relations as second-order recognition}

\author{
EL RECONOCIMIENTO EN LAS \\ SOCIEDADES MULTICULTURALES \\ Relaciones intergrupales y reconomiento \\ de segundo orden
}

\author{
Benno Herzog ${ }^{1}$ \\ Departamento de Sociología y Antropología Social, Universitat de València \\ benno.herzog@uv.es
}

Como citar este artículo: Herzog, B. (2014), "Recognition in multicultural societies", Revista Internacional de Sociología, 73 (2), 2015.

doi: http://dx.doi.org/10.3989/ris.2013.07.21

\section{SUMMARY}

Since the 1990s, the notion of social recognition has developed into a key concept for sociological theory. Recognition theory seems especially promising as a means of understanding intercultural conflicts, as the sociology of intercultural relations often addresses claims of recognition of a specific identity that is different from that of the main society.

The aim of this article is to show that recognition theory can be used as a key concept in examining group inclusion in multicultural societies. Nevertheless, the existing theoretical approaches to recognition are insufficient for that purpose. Therefore, I develop my own approach to the recognition of minority groups as second-order recognition.

The concept of second-order recognition helps analyzing, understanding and evaluating conflicts in multicultural societies. It allows conflicts within groups that involve a struggle for firstorder recognition to be distinguished from conflicts between cultural minorities and the main society that involve a struggle for second-order recognition.

\section{KEYWORDS}

Axel Honneth; Multiculturalism; Recognition; Social conflicts.
Copyright: ( 2015 CSIC. Este artículo de acceso abierto distribuido bajo los términos de la licencia Creative Commons Attribution-Non Commercial (by-cn) Spain 3.0.

Recibido: 21/07/2013. Aceptado: 21/03/2014

\section{RESUMEN}

Desde los años 90, la noción de reconocimiento social se ha convertido en un concepto clave para la teoría sociológica. La teoría del reconocimiento parece especialmente prometedora para entender conflictos interculturales puesto que la sociología de las relaciones interculturales a menudo aborda reivindicaciones de reconocimiento de identidades particulares, diferentes de las del resto de la sociedad.

El objetivo de este artículo es mostrar que la teoría del reconocimiento puede ser utilizada como concepto clave para analizar la inclusión de grupos en sociedades multiculturales. No obstante, los enfoques teóricos existentes son insuficientes para este cometido. Por ello desarrollaré mi propio enfoque de reconocimiento de grupos minoritarios como reconocimiento de segundo-orden.

El concepto de reconocimiento de segundo orden ayuda a analizar, entender y evaluar conflictos en sociedades multiculturales. Permite diferenciar entre conflictos dentro de grupos (reconocimiento de primer orden) y conflictos entre minorías culturales y el resto de la sociedad, como luchas de reconocimiento de segundo orden.

\section{Palabras Clave}

Axel Honneth; Conflictos sociales; Multiculturalismo; Reconocimiento.

\footnotetext{
1 Acknowledgments: I warmly thank Francesc Hernàndez for his suggestions on this paper and for his support in recent years. Likewise, I would like to thank Titus Stahl, Isabella Muzio, and the participants of the Social Theory Conference of the European Sociological Association held in Athens, Greece, September 6 - 8, 2012 for their inspiring and helpful comments on an earlier version of this paper.
} 
Since the 1990s, the notion of social recognition has developed into a key concept for social and sociological theory (Fraser 2003; Honneth 1992; Ricoeur 2005; Taylor 1994). This concept suggests that individuals create, shape, and confirm their identity as autonomous subjects in interactions with other persons and institutions. It is therefore a matter of vital interests, justice, and social liberty (Honneth 2011) to create social and institutional settings that allow individuals to find themselves recognized. Unlike some classical liberal theories that start with individuals and then address the question of how these individuals could best organize their mode of living, recognition theory is grounded in real, existing social interactions and demands for recognition. Unlike the utopian views of those who argue for justice without taking into account the pre-existing, intuitive ideas about justice that are dominant in a given society, recognition theory is more likely to be accepted by society because it is grounded in pre-existing intuitions of justice. Moreover, its reference to intersubjectivity and the analysis of pre-existing institutions makes recognition a genuine sociological concept, as it is now possible to analyze social reality in terms of whether it offers individuals the opportunity to develop an autonomous, recognized personality.

A good definition of recognition for our purpose was brought into debate by lkähimo (2002) and aims to differentiate recognition as a term for social and political philosophy from the everyday notion of recognition as apprehension or simply respect. Although there are, of course, differences in the use of the recognition concept, we could take this definition as a good starting point. Following Ikäheimo, recognition is "a case of $A$ taking $B$ as $C$ in the dimension of $D$, and B taking A as a relevant judge" (450). Here, several aspects could be underlined:

1. Recognition as a term referring to persons, that is human beings with specific characteristics which could be granted (recognized) or not. In this sense, when we recognize, for example, someone's right to express his opinion, we recognize the human being as a person with that right.

2. Recognition is a notion of social interaction in a double sense:

a) A person cannot be recognized only by itself, there has to be at least one person or institution which has to recognize the other.

b) The recognizing institution/person has to be in a certain sense recognized by the other as able to provide true recognition.

Although recognition theory in all of its dominant variants aims at individuals involved in processes of mutual recognition (see also Zurn 2003), the theory of recognition "always presupposes a horizon of collectivity" (Heins 2010: 161). Struggles for recognition therefore are always struggles for a community and for inclusion. Furthermore, there are some aspects of recognition theory that make it especially promising in terms of processes of group inclusion. Recognition theory can serve as a means of understanding intercultural conflicts, as the sociology of intercultural relations often addresses claims of recognition of a specific identity that is different from that of the main society. In looking closely at that "politics of identity", we can see that this term covers a broad spectrum of legal, economic, personal or collective recognition that directly affects an individual's relation-to-self: his or her self-confidence, selfrespect and self-esteem. Recognition here seems to be a promising concept for multiculturalism, as it is able to combine equality and difference, similarity and distinction. We are all equal in that we all need love/friendship, rights/respect and esteem. We are also all equal because we need these forms of recognition to create our own autonomy and our own successful relationship to ourselves through selfconfidence, self-respect and self-esteem. Simultaneously, we are also different: we have different primary relationships, sometimes we have differentiated rights, and esteem is granted on the basis of individual merit. As van den Brink and Owen (2007) state:

In relations of recognition, subjects reassure others and themselves of their similarity with regard to their being persons who all have similar needs, capacities, and abilities, which can only be sustained and further developed through intersubjective relations. At the same time, these dependent and in important respects, similar persons reassure themselves and others of their status as distinct individuals. (p. 4)

Nevertheless, due to the direct link between recognition theory and personal identity and individual autonomy, recognition theory has seldom been used successfully to understand the recognition of groups. Although Taylor prominently addresses the problem of multicultural recognition in his famous article (Taylor 1994), the broader and more explicit notion of recognition by Axel Honneth has not yet been used for cases of group recognition. In only one article (Honneth 2001) and one interview (Honneth 2006) does Honneth talk directly about aspects of multicultural recognition. What is more, in his dispute with Nancy Fraser, Honneth discusses the problem of recognizing specific cultural identities denying the possibility of a fourth principle of recognition by understanding group claims ultimately as the claims of its members, not grasping the sociological complexity of groups as social actors (Honneth in Fraser and Honneth 2003: 161-170).

The aim of this article is to show that recognition theory can be used as a key concept in examining sociological phenomena linked to questions of group inclusion. Nevertheless, the existing theoretical approaches to recognition are insufficient for that purpose. Therefore, I develop my own ap- 
proach to the recognition of minority groups as second-order recognition, which combined with Axel Honneth's broader notion of recognition, facilitates the understanding of group recognition. The notion of second-order recognition as it is presented here can be used to better analyze intercultural relations. Moreover, this notion can be used to normatively evaluate inter-group relations as practices of second-order recognition. On this basis, Honneth's recognition theory becomes applicable to processes of group recognition.

In the first section, I will show how the concept of recognition has developed over time and how it can be used to understand the processes involved in intercultural relations (I). Using common criticisms of the applicability of the recognition concept for multicultural purposes, I will suggest a view of second-order recognition that will aid us in understanding the recognition of cultural groups (section II). I will then analytically develop the concept of second-order recognition and relate it to the different forms of (first-order) recognition described by Honneth so that it can be used as a tool for sociological analysis (section III).

\section{THE CONCEPT OF RECOGNITION}

Diverging from theories that were influenced by Descartes' philosophy that knowledge of the self is achieved through introspection, Hegel is usually identified as the philosopher who introduced the concept of recognition as a dialogical model of self-knowledge (McQueen 2012). Social psychologists such as Herbert Mead (1962) used the dialogical model to show that personal identity is not something original or internal but the result of a dialogical process.

When Charles Taylor explored the topic of recognition in his famous article Multiculturalism and the Politics of Recognition (Taylor 1994), he explicitly mentioned Mead as well as Hegel and the idea that "our identity is partly shaped by recognition or its absence, often by the misrecognition of others." Significantly, he insists on the "real" or material aspect of this identity: "And so, a person or group of people can suffer real damage, real distortion if the people or society around them mirror back to them a confining or demeaning or contemptible picture of themselves." (p. 25) Therefore, for Taylor, recognition is "a vital human need" (p. 26). Here, it is clear that misrecognition ought to be viewed as an important social problem because it damages one's relation-to-self.

I view Taylor's approach as narrow because he concentrates only on one sphere and two modes of recognition. Taylor states that there are two spheres of recognition: the "intimate sphere" and the "public sphere" (p. 37). Although he recognizes that "[c]ertain feminist theories have tried to show the links between the two spheres" (ibid.), he only concentrates on the public sphere as the space for the politics of equal recognition. However, when talking about the "politics of recognition", Taylor should be aware that there are very important framework decisions to be made about how the state or society shapes the conditions for the private sphere. Contemporary debates center on questions such as the following. To what degree should the state be able to intervene in the decisions of parents to educate their children (e.g., religious fanatics who want to raise their children apart from or against society)? What type of intimate spheres should be protected (as in the debates about homosexual marriages and adoption rights)? To what degree should society positively intervene in families through welfare politics (e.g., by providing housing benefits or benefits for large families)? In addition, even if there were no link between the private and the public spheres, the private sphere as a space in which humans first receive recognition cannot be underestimated for sociological analysis. In other words, we can see how the narrowness of the notion of recognition in Taylor is a result of his exclusion of the private sphere. The roots of this strong division between public and private exist in the liberal tradition, in which the private is observed as providing freedom from social and governmental interference. However, for sociological purposes, this limitation is quite unsustainable.

I also view Taylor's version as narrow because he concentrates only on two modes of recognition. The first mode, which can also be understood as a result of Taylor's liberal tradition, is universalism and equality: the equalization of rights and entitlements. Although there is significant debate on how far-reaching equality should be and which types of natural or social inequalities should be compensated for, the idea of equal citizenship in principle is widely accepted. In contrast to or jointly with this equal recognition, Taylor imagines a second mode in which "[e]veryone should be recognized for his or her unique identity" (p. 38). This demand for recognition in the "politics of difference" based on identities or statuses that are not universally shared, seems to contradict the first mode of recognition. The demand is not that people recognize one's universal potential to create one's own identity but that they recognize the content of this identity as valuable. This demand is often formulated within multicultural contexts and often conflicts with the demand for equality, which is understood as the "sameness" of rights and treatment. The second mode is connected with the first mode in that all people are equal (the first mode) due to the mere existence of their unique or differentiated identities (the second mode). Finally, Taylor argues in favor of recognition under the presumption that cultures "that have animated whole societies over some considerable stretch of time" have an important contribution to make to the rest of society. This presumption, which would lead to a dialogue between cultures and finally to a "merging of horizons", grounds recognition in a plausible supposed potential.

Axel Honneth, who published his book The Struggle for Recognition (1992) almost at the same time, seems to use the same sources as Taylor, especially Hegel and Mead; 
he dedicates a whole chapter to the latter. However, unlike Taylor, Honneth does not use the Phenomenology of Spirit as his main text; rather, he uses Hegel's Jena Phenomenology and later also the Philosophy of Rights (Honneth 2000, 2011). From these writings, Honneth draws his three spheres and three modes of recognition. I will therefore refer to his concept of recognition as the broad approach.

Following Hegel, in the family, individuals are recognized as having concrete needs in the mode of love. In civil society, the formal autonomy of persons is recognized by their rights, and in the state, affective intuition about the family and the cognitive concept of rights are somehow sublated (aufgehoben) ${ }^{2}$ in intellectual intuition (or the "affect made rational") in the third sphere: the state. Here, the mode of recognition is solidarity between subjects with specific individuality (see also Hernàndez and Herzog 2011; Pippin 2007). However, unlike Hegel, Honneth does not see these three spheres as partaking in a process in which one sphere leads to the creation of another, which finally comes to an end with the (Prussian) state. For Honneth, in modern societies there are three parallel and interwoven spheres with three equally important modes of recognition.

What is important for Honneth is that every sphere corresponds to one specific dimension of personality and practical self-relation. For successful self-relation, one has to experience recognition in all three spheres. Otherwise, one component of one's personality is threatened. Honneth summarizes his approach as shown in Table 1 (Honneth 1992: 129 - slightly expanded):

Here, we can observe the three spheres of recognition and how each of these spheres corresponds to different modes of recognition: emotional support, cognitive respect and social esteem. Each of these modes in our society is linked to a specific form of recognition. This is why most authors such as Thomson (2006) do not differentiate between modes and forms and instead speak directly of the following three modes: love, respect, and esteem. As we can see, for

2 For information regarding the complex meaning and translation of aufheben and Aufhebung see Froeb (2012).
Honneth, there is a developmental potential in the different modes of recognition, which is one reason why the process or the "struggle" for recognition has not yet come to an end: love in families can be liberated from economic pressures (Honneth in Fraser and Honneth 2003: 139), and rights can be generalized or esteem can be distributed in a more individualized way. What is important is that all of these modes refer to specific dimensions of personality and that if one part of a person's personality is disrespected, that disrespect can lead not only to social disintegration but also to serious damage to one's self-relation.

Regarding the idea of multicultural recognition, Honneth's proposal suggests the potential to combine equality (equal rights) and differentiated recognition in the form of social esteem based on merit. However, Honneth's approach to diversity and particular identities seems quite different from Taylor's. Unlike Taylor, for whom differentiated recognition refers to the already existing content of identities, Honneth suggests the existence of socially shared knowledge as well as a struggle about what should count as individual merit. What is recognized by Honneth is not identity but merit, although some types of merit can have important consequences for identity construction. However, this conceptualization clearly excludes some forms of identities (e.g., "race", sexual identity) that cannot be freely chosen and therefore should not be considered to generate social esteem.

\section{Problems of multicultural ReCognition and the CONCEPT OF SECOND-ORDER RECOGNITION}

In order to develop a concept of recognition which could be used for the inclusion of groups, I will discuss some problems linked to the application of the model of recognition towards social groups. The critics are ultimately linked to the risk of reification of the sources of recognition. Instead of proposing an original point of the sources of recognition, I will try to integrate these sources of recognition with my concept of second-order recognition which either resolves or avoids the problems discussed.

Table 1.

Honneth's Theory of Recognition

\begin{tabular}{llll}
\hline $\begin{array}{l}\text { Sphere of recognition } \\
\text { Mode of recognition }\end{array}$ & Family & State & Society \\
Dimension of personality & Emotional support & Cognitive respect & Social esteem \\
Forms of recognition & Primary relationships (love, friendship) & Logal relation (rights) & Traits and abilities \\
Developmental potential & e.g., Freedom from economic restrictions & Generalization, de-formalization & Community of value (solidarity) \\
Practical relation-to-self & Basic self-confidence & Self-respect & Individualization, equalization \\
Forms of disrespect & Abuse and rape & Denial of rights, exclusion & Denigration, insult \\
Threatened component of personality & Physical integrity & Social integrity & 'Honor', dignity \\
\hline
\end{tabular}




\section{1) Resolving the problem of the source of recognition}

When applying the concept of recognition towards groups, there is the danger of understanding the (potential) value of a specific contribution, as somehow original, pre-existing or created by the cultural group itself without further contact with the rest of the society. This would suggest some form of consensus within the community about the character of the community (Sánchez-Dura 2007) and the idea of authenticity of that specific group. McQueen (2012), following Laitinen (2002) and Markell (2007), calls this model the responsive model. Whereas in the generation model, the focus is on what identities are produced through recognition and how this occurs, the responsive model advocates acknowledging someone "as they already really are" (Appiah 1994: 149). This model could lead to a reification of the group as if it were a static entity. Not only is this conceptualization faulty because groups constantly create, develop, and change their identities, but it can also lead to the coercion of the members of a community, who are convinced to behave in a real, authentic or proper way. As Appiah notes, this type of structure would only replace "one kind of tyranny with another" (Appiah 1994: 163).

Members of a group develop their practices, beliefs, and habits through a process of socialization in which recognition itself is essential. Recognition is vital to the creation of one's identity, not only in contact with the rest of society but also within the group itself. Therefore, a person needs such recognition to develop a comfortable identity as a member of the group. In other words, what is to be recognized by the rest of society is itself the result of an (internal) process of recognition. We can therefore speak of the recognition of cultural minorities by the main society as second-order recognition. The main society will then recognize specific practices or patterns in how minority groups organize recognition. For example, we could recognize the specific type of love and care that African women in western societies give to their children even though they often have a heavy workload inside and outside their families. In this specific form of recognition, the recognizer does not indicate a desire to adopt that family model for himself/herself; he or she simply expresses respect for a specific solution to the more general problem of raising children. Thus, secondorder recognition is not a doubling of recognition; we do not share the specific love or commitment of the other but instead simply recognize it as valuable.

Another example of second-order recognition is the recognition of how members of a religious group grant equal respect to each other based on the idea that before God, we are all equal. We do not have to share that religious conviction to recognize the specific practice of upholding equality as valuable. We can understand the importance of equality for the members of the group and recognize the specific solution that the religious group has found to the problem of equality. In the same way, we could recognize how individuals in the group are esteemed based on their individual contribution without sharing this esteem for the contribution.

One argument against this approach to second-order recognition is that with this concept, we are again abandoning the dialogical model. The main society recognizes something (second-order recognition) that already exists, although this time, the existing characteristic is the product of a process of first-order recognition. However, when collective claims for recognition are made towards the main society and its institutions, particular groups and main society are again engaging in dialogue. What is more, at the moment a particular group makes a claim towards the main society, it is implicitly recognizing the main society as a competent dialogue partner.

The so produced second-order recognition is the basis upon which first-order recognition takes place. Secondorder recognition is the framework that is required in this society for groups to successfully build their own identities. For first-order recognition to be effective, a specific material, ideological, or juridical infrastructure is required. This infrastructure, which allows the cultural group to organize recognition according to its own rules, can be interpreted as a form of - dialogically constructed - recognition of the minority group. For a group to organize recognition, the broader society has to protect specific rights such as religious freedom or material infrastructure, for example, by providing meeting places for the community.

\section{2) Avoiding the problem of the limits of the group}

The second problem is closely linked to the idea of group characteristics as authentic. It is unclear how we can identify those cultures or groups who will be the object of recognition. Taylor, for example, refers to cultures "that have animated whole societies over some considerable stretch of time" as candidates for group recognition. Here it seems that this approach views "cultures" as an authentic and more or less invariant group. But as seen in the previous examples, we were not recognizing a whole group or culture; we were only recognizing a specific, concrete practice. Of course, we know that specific practices are embedded in particular cultural contexts, but in the same way that cultures change over time, their practices change over time, and we could approach every single practice of a culture with Taylor's presumption that that practice is an important contribution (i.e., an important form of recognition).

One example of such a specific practice is bullfighting, which is part of the Spanish tradition in most regions of Spain and some regions of Latin America. This practice is viewed by most western observers as cruel to animals and is therefore rejected. Nevertheless, we could view this practice with the presumption that it makes an important 
contribution and ask what the practice offers to bullfighters and spectators in terms of recognition. We can easily see the specific recognition of the bullfighter due to his physical capacities and bravery; in addition, the spectators recognize their common identity, which also connects them with a specific cultural tradition. These aspects of the experience are all positive for the people involved, although we may not share bravery as an ideal or as a basis for recognition, or we may even think that bullfighting is not brave at all but rather is foolish or cowardly. In other words, without recognizing the legitimacy of the practices themselves, we can develop a type of second-order recognition not of the practice itself but rather of other individuals' recognition of it.

Now, we can ask whether our 'recognition of recognition' based on physical capacities and bravery really requires the practice of killing bulls. Other forms of public spectacle could be imagined that would provide the positive aspects of the bullfight without the negative ones. I am thinking here of the tradition that arose in response to the criticisms of bullfights in the south of France. In this tradition, instead of hurting and killing a bull, people try to fool the animal by jumping over it and "playing" with the bull. In this somehow sublated form of bullfighting, recognition for the "bullfighter" is still based on physical capacities and bravery, and the spectators still feel the common identity connected to the long tradition of bullfighting. Secondorder recognition by the rest of society can foster this type of cultural practice and therefore allow the specific group that practices it to seek cultural group recognition.

This example also shows that we do not recognize (or refuse to recognize) a cultural group as whole. We do not have to develop a judgment, whether final or provisional, about the whole culture. We do not even have to share the same beliefs based upon which specific recognition is distributed by a cultural group. Instead, we can pick out a specific (recognition) practice and evaluate the practice directly in terms of the concept of recognition and its other qualities. This process makes it easier to avoid the reification of entire groups.

\section{3) Avoiding the problem of valuing groups as a whole}

The proposal of second-order recognition also solves a third problem: common approaches to multicultural recognition are based on the presumption that relatively stable cultural groups have some important contribution to make. At least since Foucault (see, for example, Foucault 1994, 1995, 2010), we have been able to reverse that presumption and discuss the possibility that in every culture or society, there are power relations and oppression that run contrary to liberty but that guarantee stability over time. By not examining groups as a whole but instead considering concrete practices, we can disentangle different aspects of cultures. Just as we differentiated between positive and negative aspects of the bullfight, we can partially recognize or reject practices without judging the whole group positively or negatively.

\section{4) Resolving the problem of detecting the content}

These thoughts are linked to the fourth problem: the problem of approaching a whole culture as having some important contribution to make. If we directly consider the concrete contribution of a specific practice, then it is far easier to determine exactly what we value. This approach helps us to protect a specific part of the culture. Thus, we can directly value practices, persons who behave in a specific way, and groups that foster this behavior without assuming a positive stance towards the group as whole. This approach also makes it easier to reject specific practices without rejecting a group as a whole and therefore without disregarding the group or the individuals in that group.

The proposal made here still includes the presumption of an important contribution, as in the example of the bullfight. Instead of rejecting a specific practice due to its cruelty to animals, I began by considering the recognition benefits of that practice for the persons involved. I began with the (potentially counterintuitive) presumption that there is something valuable in a practice that involves hurting and killing animals as part of a public spectacle. The example showed that it is possible to analytically separate positive qualities from negative, rejected ones.

In conclusion, second-order recognition and first-order recognition allow us to identify specific practices among individual cultural groups as important to the identities and the self-images of the members of a specific group. It enables us to understand specific practices as part of the recognition of that group. Second-order recognition is a means of considering first-order recognition. It allows us to positively evaluate a recognition practice or a whole recognition framework without having to agree with the valuation of the practice itself.

We can now define second-order recognition with reference to the general definition of recognition by Ikäheimo (2002) and Margalit (2001): Second-order recognition is a case in which $A$ (person, group or institution) correctly identifies the recognitional content of a practice $P$ by a Group $B$, seeing it in a potentially public, intersubjective, and understandable act, as a practice that recognizes $C$ in the dimension of $D$, with $B$ taking $A$ as a legitimate authority.

Here, several aspects could be underlined:

3. Second-order recognition is a term that does not refer directly to persons and groups. In a first instance it refers to practices (of groups and persons) which could be valued (recognized) or not. In this sense, when we recognize, for example, a culture that organizes bullfights, we are only referring positively to the recognitional content of that practice. 
4. Second-order recognition is a notion of social interaction in a triple sense:

c) The practice itself involves (first order) recognition within the group, i.e., a dialogical way of distributing emotional support, cognitive respect, or social esteem.

d) A practice of a minority group often cannot be recognized only by the group. There has to sometimes be a larger group or an institution which has to recognize the practice in case the practice needs some specific protection.

e) The recognizing institution/group has to be in a certain sense recognized by the other as able to provide true recognition. This is usually the case as minority groups make claims for recognition towards the main society. Nevertheless, there are also some cases of extreme isolation; for example, religious groups that do not want any contact at all with the rest of the society. In the latter case we could not speak of second-order recognition.

We have observed that second-order recognition permits us to recognize diverse practices even if we do not admire those practices. This idea may sound paradoxical, but what we recognize is the recognitional content of the practice rather than the practice itself. Second-order recognition can be used to help us to positively relate to negative or false practices in a manner that is similar to the concept of tolerance that is discussed by Forst (2010). Forst criticizes one version of the concept of tolerance using Goethe's statement "to tolerate means to insult", arguing that toleration often means a certain paternalism towards the tolerated subject and therefore creates a hierarchical power structure. As an alternative to this concept, he presents his own approach to tolerance, which includes objection, acceptance and rejection:

First, a tolerated belief or practice has to be judged as false or bad to be a candidate for toleration; second [...] there have to be reasons why it would still be wrong not no tolerate these false or bad beliefs or practices - that is, reasons of acceptance. [...] And third, there have to be reasons for rejection that mark the limits of toleration. (p. 216f)

Based on this logic, a recognized belief or practice can be judged as false or negative. Nevertheless, we can often accept the recognitional content or structure linked with this practice. Finally, we can also reject other aspects of the practice, carefully balancing the negative aspects of the practice with the positive ones.

This conceptualization of recognition allows us to avoid reification in two ways. First, we understand the specific cultural practice as a result of and as embedded in the recognition order ${ }^{3}$ for that cultural group. The practice or its

3 Regarding the idea of society as recognition order see McNay (2005). evaluation by the group is constantly being recreated and therefore can change. Second, we understand first-order recognition itself as a process of recognition that creates, shapes, solidifies. or changes the basis for the practice in question and the opportunity for the group to organize intra-group recognition. In the next section, we will see how this new approach to recognition becomes clearer when combined with the broad notion of recognition presented by Axel Honneth.

\section{SECOND-ORDER RECOGNITION AS AN ANALYTICAL TOOL}

As we have observed, second-order recognition is the recognition of a specific way in which a group organizes recognition internally. The possible solutions to the problems noted in the last section justify a more in-depth analysis of the concept of second-order recognition. Some questions must be addressed if we hope to better understand the benefits that the concept can provide and the limits of the concept. Up until now, I have argued in a quite unspecific way about the "recognition" of "recognition". However, as we have observed, Honneth provides a very rich conceptual vocabulary that can be used to identify the different dimensions of recognition. In what follows, I will try to apply the three dimensions of recognition that are presented by Honneth (in what I called the broad notion of recognition) to the concept of second-order recognition. I will therefore apply the three modes of recognition to both first-order and second-order recognition.

A cultural minority often has a specific way of organizing recognition among its members. First, there are different forms of organizing emotional support among families, friends, peers, tribes, and other groups. As far as we know, all cultural groups need and grant love and friendship in some way. Second, some cultures have their own rules that are at least similar to legal relationships and that provide cognitive respect. In most cases, this cognitive respect is not tantamount to legal rights as we understand them, but nevertheless, it is at least a limited form of self-organization that is similar to rights. Third, cultural groups usually have a group-specific way of recognizing the individual contributions of its members, that is, of granting social esteem in a solidary community of values.

Members and institutions within the main society are also able to provide emotional support, cognitive respect, and social esteem. However, a question remains: is it possible to recognize all three modes of first-order recognition in all three modes of second-order recognition? What would the features of this structure be? Below, I will discuss and illustrate the possible combinations and answer the question of who is the recognizer or the recognized individual in each case. Theoretically, the following nine modes of second-order recognition should be possible (see Table 2): 
Table 2.

Possible modes of second-order recognition

\begin{tabular}{lccc}
\hline & Emotional support & $\begin{array}{c}\text { Second-order recognition } \\
\text { Cognitive respect }\end{array}$ & Social esteem \\
\hline First-order emotional support & A1 & B1 & C1 \\
First-order cognitive respect & A2 & B2 & C2 \\
First-order social esteem & A3 & B3 & C3 \\
\hline
\end{tabular}

A) Emotional support always requires a person-toperson relationship. Although people can be pleased with laws or societies, they can only love (even in a broad sense) persons. Thus, it is not possible to love recognition practices or frameworks, whether they are associated with one's own cultural group or another cultural minority group. In addition, nobody can or should be forced to love any other person. Of course, acts that usually result from emotional bonding, such as mutual care or financial aid within families, can be forced upon individuals; however, these acts are not the same as love. Consider, for example, a person who is obligated to pay alimony to his expartner but does not love her and does not provide her with emotional support. Even in cases where there is a strong normative imperative, as there is regarding emotional support for dependent family members, it is impossible to require a person to love another person. If this is true about love towards persons, then it is also true a fortiori about love towards recognition structures. Moreover, recognition practices or structures, independently of whether they are related to emotional support, cognitive respect, or social esteem, do not require emotional support. So, for example, an internal rule of a minority group perhaps does require different types of support from the rest of the society as we will see in the next paragraphs, but does not need to be emotionally supported by the main society.

B) Although the model of second-order recognition seems not to hold for love as the second-order recognition of any first-order recognition practice, the same is not true of respect as a mode of second-order recognition. Here, in all cases, the recognizer is a superior legal organization (typically the state) that grants rights. Nevertheless, the recognized can be practices of individuals, groups or community institutions, as we will see when we examine the concept of second-order recognition:

B1) Organizations that grant emotional support (typically families but also friends, tribes, etc.) often seem to need a legal framework in order to protect themselves against external impositions. To love and care autonomously for other persons requires some external resources. Thus, states usually have family codes that provide the foundation for emotional support. These codes often make provisions for financial aid when one is caring for dependent family members as well as time resources such as the right to parental leave or specific legal rights for individuals in relation to their direct family members. For instance, they might be granted special rights such as the right to make decisions for underage or incapacitated family members or the right to care for them even after one's own death through terms specified in a will. Second-order recognition in this case could mean the legal recognition of traditionally or culturally differentiated forms of loving and caring through privileges for individuals who are involved in the caring process. One example would be the extension of the previously mentioned legal rights to individuals from the broader community in those cultural groups, in which primary emotional support is given by the whole community.

Whereas in this case, those who receive special rights are individual members of cultural groups, it is also possible to think about larger units as holders of rights. For instance, in tax policies, the family unit or the people living together under one roof are often considered together. It might make sense to extend the notion of a primary unit to a larger community whenever the culturally specific notion of living, caring, or loving seems to apply to a larger community than the western model of the nuclear family.

In summary, multicultural second-order recognition requires a broadened and adapted legal framework for emotional support in accordance with the practices of specific cultural groups. The main society is not obligated to value the specific way of providing love and care that is exercised in the cultural minority group, but the society must recognize that method as a possible solution to the problem of emotional support.

B2) The case of legal support by legal or quasi-legal structures in cultural groups is somewhat more complicated. Second-order recognition in this case could mean the legal recognition of culturally specific or traditional ways of addressing community issues based on a group's own legal rules. This is the question of the right to self-government, about which there has been significant public debate. Issues such as the "cultural right" to perform genital mutilation, obligatory prayer, or mass attendance for members of religious groups, and the right to organize public services in 
languages different from the language of the main society are all relevant to this topic. If we allow group-differentiated rights, then we face the problem of differentiating "bad" minority rights from "good" ones (Kymilicka 1995, 2002). On the one hand, Kymlicka differentiates between "internal restrictions", which are those rights that allow the community to restrict the individual privileges of its members; for example, the obligation to wear certain clothes or to not choose one's own partner. On the other hand, Kymlicka identifies rights that provide protection against external pressure. Those rights do not limit individual rights but instead supplement them. They are usually intended to counter unfairness between groups. Language rights are one example of this type of rights; they protect a linguistic minority from being marginalized for linguistic reasons in the public sphere.

It is not difficult to imagine Kymlicka's response to the question of minority rights. He states, "Given the commitment to individual autonomy I believe that liberals should be skeptical of claims to internal restriction" (Kymlicka 2002: 342). Furthermore, "minority rights are consistent with liberal culturalism if (a) they protect the freedom of individual within the group; and (b) they promote relation of equality (non-dominance) between groups" (ibid).

In this sense, second-order recognition could mean limited legal recognition of community-based regulations. Only those regulations that do not restrict fundamental individual freedoms could be recognized. In practice, however, minority groups are often quite skeptical of this solution because it seems to create the need for a Supreme Court based within the main society that is able to rule over the legality of the regulations of the minority group. The long history of repression and cultural misunderstanding has shown that mainstream society and its legal representatives are often far from being neutral in evaluating the practices of cultural minorities. One solution here could be to establish international courts that function as arbiters for such cases and make decisions based on human rights.

B3) The idea of second-order recognition as cognitive respect for specific cultural patterns of organizing esteem seems less complicated. This type of second-order recognition legally protects culturally differentiated ways of recognizing an individual's contribution to the other members of a group. This form of second-order recognition is quite uncomplicated because both the main society and the minority groups recognize their members based on individual merit. In the main society, there are different ideas about what should count as merit and how it should be recognized. Questions that are discussed in western societies include the following. What is the worth of domestic work in one's own household, and should this work be recognized using financial compensation? Should graduates from a lower-class background be favored in selection processes because it is more impressive for a person to have graduated from school while living in a disadvantageous economic and cultural context? These examples of debates within mainstream society indicate the extent of the disagreement. It is uncontested that merit should be recognized, but what counts as merit is highly disputed. Only a truly ignorant individual would simply disregard other ways of conceptualizing merit.

In this context, it is irrelevant whether the cultural group recognizes the merits of hard work, complex work or household work; being intelligent, brave or funny; having lots of children; being artistic; or living a life devoted to other humans, to God or to the nation. The important issue here is that every group needs to institutionalize a system for granting esteem based on merit. This institutionalization process can be considered just when every member has the opportunity to participate in practices that are viewed as valuable in the community of value.

Second-order recognition here would mean that the legal institutions of the main society allow and protect alternative means of distributing social esteem based on respect. For example, if a social group decides that having many children or dedicating significant time to them by raising them on their own counts as merit, then this group should have the right to redistribute its resources to favor people who have more children or who dedicate more time to them. Again, the concept of second-order recognition also has limits. In this case, a way of distributing social esteem that disrespects community members based on characteristics that cannot be viewed as individual merits (for example, skin color) would not be tolerated.

C) As previously mentioned, social esteem is based on merit. For Honneth, social esteem can be symbolic as well as material. (This is one of the main differences between Honneth and authors like Nancy Fraser, who understand recognition in terms of the politics of identity as symbolic politics and therefore demand a politics of redistribution). A reliable worker can receive a simple "well done" from his superiors or colleagues, he can be made employee of the month, he can ascend in the hierarchy of the company, or he can receive extra pay. Merit is also a legal principle, at least in the public sector, in which job candidates must be selected on the basis of merit. For our purpose, in examining the concept of second-order recognition, we can understand a valuable practice as follows:

C1) A practice that provides emotional support and recognition (such a practice would be very similar to the process discussed under B1). Here too, legal rights can be used to recognize a specific way of loving and caring practiced in a minority group. The differences here are as follows:

a) There are other forms of showing esteem, such as symbolic politics, which are similar to the verbal 
commendation described before. Here, we might publicly value the method of loving and caring that is used in the minority group. This public recognition could mean, for example, pointing out the merit of alternative forms of caring found in larger communities, tribes, homosexual partnerships, or other collective units. Again, the main society need not indicate that it wishes to copy or imitate the practice in question. As we have observed before, this type of symbolic politics is not only an ideological superstructure, it is also the basis on which individuals can develop a positive sense of self-relation, as their practices are interpreted as valuable not only directly by the members of the cultural group but also indirectly as practices of recognition within the broader society. We could also similarly conceptualize a material form of recognition in which esteem for alternative forms of emotional support leads to economic redistribution.

b) The reason for the type of esteem for emotional support is quite different from the reason for cognitive respect for the same support. Whereas in the first case, the reason for esteem is the specific merit of the unique form of organizing emotional support, in the case of legal support, the argument is about equality: for every individual and group to be able to organize emotional support equally, some cultural groups need specific protection for their practices.
C2) A legal practice that assures equal recognition. Again, instead of legally protecting group laws or internal regulations, we can also honor them for their specific contribution. This act might include financial support, legal support, or "only" symbolic support for the legal structure of the cultural group.

C3) A practice that expresses esteem for members of the same cultural group. Clearly, we can also legally, symbolically, or economically "honor" the practice of distributing esteem between members of a group.

In all cases in group $\mathrm{C}$, we show esteem for a particular contribution, a particular solution within a group to the general problems of distributing love, respect, and esteem. When we show (second-order) esteem for a specific contribution of a cultural group, we recognize the merit of the alternative cultural practice not only for the group itself but also for the rest of society. A practice by a cultural minority has merit for the whole society because it presents an alternative mode of behavior/social organization and therefore broadens the possibilities for all individuals within the society. In other words, the mere existence of alternative forms of differentiated (first-order) recognition is valuable to the whole society because it provides greater liberty for all of its members. In all three cases, the main society, its institutions, and its individuals are implicated as recognizing actors in the process.

The following table summarizes the concept of secondorder recognition in the nine possible modes.

Table 3.

Modes of second-order recognition

\begin{tabular}{|c|c|c|c|}
\hline & \multicolumn{3}{|c|}{ Second-order recognition } \\
\hline & Emotional support & Cognitive respect & Social esteem \\
\hline First-order emotional support & $\begin{array}{l}\text { 1. Emotional support for any form of } \\
\text { first-order recognition cannot be conver- } \\
\text { ted into a normative obligation. }\end{array}$ & $\begin{array}{l}\text { e.g., Legal support for traditional forms } \\
\text { of caring }\end{array}$ & $\begin{array}{l}\text { e.g., Symbolic and material recognition } \\
\text { (i.e., through redistribution) for tradi- } \\
\text { tional caring practices because of the } \\
\text { specific contribution of this culture }\end{array}$ \\
\hline First-order cognitive respect & $\begin{array}{l}\text { 2. Emotional support for any form of } \\
\text { first-order recognition should not be } \\
\text { converted into a normative obligation. }\end{array}$ & $\begin{array}{l}\text { e.g., Legal support for a community- } \\
\text { based legal structure }\end{array}$ & $\begin{array}{l}\text { e.g., Symbolic and material recognition } \\
\text { (i.e., through redistribution) for limited } \\
\text { self-government }\end{array}$ \\
\hline First-order social esteem & $\begin{array}{l}\text { 3. Any form of first-order recognition } \\
\text { does not require emotional support from } \\
\text { outside. }\end{array}$ & $\begin{array}{l}\text { e.g., Legal support for culturally specific } \\
\text { modes of granting esteem (communi- } \\
\text { ties of values) }\end{array}$ & $\begin{array}{l}\text { e.g., Symbolic and material recognition } \\
\text { (i.e., through redistribution) for commu- } \\
\text { nity values. }\end{array}$ \\
\hline
\end{tabular}


As we have observed, the concept of second-order recognition can be used as an analytical tool for understanding how mainstream society can relate to the specific practices of cultural minorities. If we understand cultural practices as practices of recognition, the main society can relate to these practices in a positive way, recognizing them in legal, symbolic, or material terms. We have also observed that such recognition does not require an emotional response to these practices. Finally, we have been able to trace the limits of recognition. Where culturally specific practices interfere with the physical integrity, social integrity, or dignity of individual members, they should not be protected by second-order recognition. In other words, second-order recognition aims to combat individual suffering that stems from unjust social situations. In those cases where there is an increase of suffering and where there is first-order disrespect instead of first-order recognition, the second-order response to these practices must be rejection rather than recognition. What is more, the notion of second-order recognition can also be used to address diversity within minority groups. In other words, minorities within minorities, those that do not agree with some of the practices of the minority group as a whole, also require some form of second-order recognition to organize practices of (first-order) recognition among themselves.

The $3 \times 3$ matrix of theoretically possible ways of understanding second-order recognition (and the corresponding $2 \times 3$ matrix of actual possibilities) also shows the entanglement of the different types of recognition within multicultural societies. It is impossible to neatly separate the three spheres of recognition, as all of the spheres require legal protection and need to be considered valuable so that they can be preserved and permit the individuals within them to develop a positive self-relation.

We now are able to see why I opted for the term secondorder recognition instead of others ${ }^{4}$ for describing this secondorder approach toward groups. I did so for two reasons: First, to state its inseparable link to (first-order) recognition. Secondorder recognition is not any kind of recognition of the majority towards minority groups but only recognition that refers to the recognitional content of practices of first-order recognition. Second, I chose the term in order to underline its analytical similarity to two modes of recognition in the theory of Axel Honneth, namely cognitive respect and social esteem.

\section{ConcLusions}

The concept of second-order recognition is a powerful tool for analyzing, understanding, and evaluating conflicts in multicultural societies. This concept allows conflicts within

4 Pensky (2007, 2008), for example, speaks of "secondorder inclusión" when refering to transnational solidarity and group's inclusion as well as deliberative justified exclusion. groups that involve a struggle for first-order recognition to be distinguished from conflicts between cultural minorities and the main society that involve a struggle for second-order recognition. Second-order recognition not only serves as a valid concept within social and political philosophy, it is also meant to be a genuine sociological concept. The scheme presented in Table 3 allows us to analyze real, existing practices of recognition and rejection of cultural groups. What is more, we can evaluate the claims to recognition made by minority groups. This classification will help us to understand what is at stake in each case of multicultural conflict.

Furthermore, second-order recognition has positive secondary effects, and understanding some conflicts in multicultural societies in this manner can help us to foster these effects. First, a society that recognizes cultural minorities will be able to more easily generate positive self-relation due to the mutual character of recognition. The main society and its members are mirrored by their own cultural groups as a liberal or tolerant society and not as an oppressive one. Second, this process of struggling for second-order recognition leads to an increase in intergroup relations. On the one hand, members of the main society try to understand the recognitional content of the practices of cultural minorities. On the other hand, minority groups, by conferring power to the main society, are also recognizing it in a specific way. This increase in inter-group relations could lead to the merging of horizons. Third, by recognizing (i.e., positively evaluating) at least the recognitional content of specific practices, all members of a society become familiar with alternative ways of organizing first-order recognition. This increase in possibilities can be understood as an increase in freedom. Finally, although the recognition of differentiated practices has important effects on the identity of specific cultural groups, second-order recognition can also help to create a common (e.g., national) identity and can thus help to create solidarity between members and groups of the society as a whole (on the importance of the struggles themselves see also Tully 2000).

However, there are still some questions that could inspire further research about the concept of second-order recognition. For example, one question relates to the internal diversity of cultural groups. What if certain members of the group seeking second-order recognition do not identify with the rules according to which the group organizes recognition? Is there no danger of reifying groups and group practices? We have already discussed some cases of clear first-order disrespect that should not be protected by second-order recognition. However, what happens if there is no clear response to the practices of first-order recognition and disrespect? What is the role of the main society in this internal struggle for recognition? Here, we might examine topics such as the opportunity for individuals of cultural groups to effect change within their own groups and the potential for individuals to leave their cultural groups. 
Another open question is whether the concept presented here is useful for all types of cultural minorities. As Emcke (2000) pointed out, there is an important difference between groups with chosen identities (e.g., Buddhists) and those with imposed ones (e.g., African Americans).

Further theoretical and sociological work must determine what types of social and individual pathologies are connected to the lack of second-order recognition (on pathologies see also Zurn 2005). A lack of second-order recognition affects the opportunities for groups to organize first-order recognition, which can generate disrespect towards individuals. It could also be suggested that, as in dialogical processes of personal identity creation, the creation of group identity and the position of cultural groups within society depend on second-order recognition. The concept of second-order recognition is a promising means to understand conflicts and disrespect in multicultural societies and is worthy of further examination.

\section{References}

Appiah, K. A. 1994. "Identity, Authenticity, Survival: Multicultural Societies and Social Reproduction." In: Multiculturalism Examining the politics of recognition. Edited by A. Gutmann, Princeton: Princeton University Press 149-163.

Emcke, C. 2000. "Between Choice and Coercion: Identities, Injuries, and Different Forms of Recognition." Constellations 7(4): 483-495. http://dx.doi.org/10.1111/1467-8675.00204

Forst, R., 2007. "To Tolerate Means to Insult: Toleration, Recognition, and Emancipation." In: Recognition and Power. Axel Honneth and the Tradition of Critical Social Theory. Edited by B. Van den Brink, and D. Owen, Cambridge: Cambridge University Press 215-237. http://dx.doi.org/10.1017/CBO9780511498732.009

Foucault, M. 1994. The Order of the Things. An Archeology of Human Sciences. New York: Random House.

Foucault, M. 1995. Discipline \& Punish. The Birth of the Prison. New York: Random House.

Foucault, M. 2010. "The Government of Self and Others." Lectures at the Collège de France 1982-1983 New York: Palgrave McMillan.

Fraser, N. and Axel Honneth 2003. Redistribution or Recognition? A Political-Philosophical Exchange. London: Verso.

Froeb, K. 2012. "Sublation." In: hegel.net, online resource. Available at: http://www.hegel.net/en/sublation.htm. Date of access: 02/07/2013.

Heins, V. 2010. "Of persons and peoples: Internationalizing the critical theory of recognition." Contemporary Political Theory, 9(2): 149-170. http://dx.doi.org/10.1057/cpt.2008.48

Hernàndez, F. and Benno Herzog 2011. "Axel Honneth: Estaciones hacia una teoría crítica del reconocimiento." In La sociedad del desprecio. Edited by F. Hernàndez and B. Herzog, Madrid: Trotta: 9-38.

Honneth, A. 1992. Der Kampf um Anerkennung. Zur moralischen Grammatik sozialer Konflikte. Franfkurt: Suhrkamp. [English: Honneth, A. 1995.The Struggle for Recognition: The Moral Grammar of Social Conflicts. Cambridge: Polity Press.]

Honneth, A. 2000. Suffering from Indeterminacy. An attempt at a reactualization of Hegel's Philosophy of Right. Amsterdam: Van Gorcum.
Honneth, A. 2001. "Invisibility: On the Epistemology of Recognition." Aristotelian Society Supplementary, Vol 75(1): 111-126. http://dx.doi.org/10.1111/1467-8349.00081

Honneth, A. 2006 "Rassismus als Sozialisationsdefekt. Ein Gespräch von Krassimir Stojanov mit Axel Honneth." Critique \& Humanism, 22: 155-160.

Honneth, A. 2011. Das Recht der Freiheit. Frankfurt: Suhrkamp.

Ikäheimo, H., 2002. "On the Genus and Species of Recognition." Inquiry, 45: 447-462. http://dx.doi.org/10.1080/002017402320947540

Kymlicka, W. 1995. Multicultural Citizenship. Oxford: Oxford University Press.

Kymlicka, W. 2002. "Multiculturalism." In: (ibid.) Contemporary political philosophy - An introduction. Oxford: Oxford University Press: 327-376.

Laitinen, A. 2002. "Interpersonal Recognition: A Response to Value or a Precondition of Personhood?" Inquiry, 45: 463-478. http://dx.doi.org/10.1080/002017402320947559

Markell, P. 2007. "The Potential and the Actual: Mead, Honneth, and the I." In: Recognition and Power. Axel Honneth and the Tradition of Critical Social Theory. Edited by B. Van den Brink, and D. Owen, Cambridge: Cambridge University Press: 100-134. http://dx.doi.org/10.1017/CBO9780511498732.005

McQueen, P. 2012. "Social and Political Recognition." In Internet Encyclopedia of Philosophy. http://www.iep.utm.edu/recog_sp Date of access: 02/07/2013.

Pensky, M. 2007. "Two Cheers for Cosmopolitanism: Cosmopolitan Solidarity as Second-Order Inclusion." Journal of Social Philosophy, Vol. 38(1): 165-184. http://dx.doi.org/10.1111/j.1467-9833.2007.00372.x

Pensky, M. 2008. The ends of solidarity: discourse theory in ethics and politics. New York: State University of New York Press.

Pippin, R. 2007. "Recognition and Reconciliation: Actualized Agency in Hegel's Jena Phenomenology." In: Recognition and Power. Axel Honneth and the Tradition of Critical Social Theory. Edited by B. Van den Brink, and D. Owen, Cambridge: Cambridge University Press: 57-78. http://dx.doi.org/10.1017/CBO9780511498732.003

Ricoeur, D. 2005. The course of recognition. Cambridge/London: Harvard University Press.

Sánchez-Dura, N. 2007. "¿Qué cultura debe reconocerse en la política multicultural?" Recerca 7: 127-144.

Taylor, C. 1994. Multiculturalism - Examining the politics of recognition. Princeton: University Press.

Tully, J. 2000. "Struggles over Recognition and Distribution." Constellations 7(4): 469-482. http://dx.doi.org/10.1111/1467-8675.00203

Van den Brink, B. and David Owen (eds.) 2007. Recognition and Power. Axel Honneth and the Tradition of Critical Social Theory. Cambridge: Cambridge University Press.

Zurn, C. F. 2003. "Identity or Status? Struggles over 'Recognition' in Fraser, Honneth, and Taylor." Constellations 10(4): 519-537. http://dx.doi.org/10.1046/j.1351-0487.2003.00351.x

Zurn, C. F. 2011. "Social Pathologies as Second-Order Disorders". In: Axel Honneth: Critical Essays, edited by D. Petherbridge, Leiden: Brill: 345-370.

http://dx.doi.org/10.1163/ej.9789004208858.i-439.80

BENNO HERZOG $(\mathrm{PhD})$ is professor for social theory and methods of social research at the Department of Sociology at the University of Valencia (Spain) and Lecturer at the International Summer School on Global Health and Migration. He worked and conducted research in Germany (University of Frankfurt, University of Mainz), in the UK (University of Manchester, Open University) and Brazil (Federal University of Paraiba). His research is focused on Critical Theory and theories on recognition, migration, racism and discourse studies. 